\title{
Effect of Sowing Date, Host Cultivar, and Race of Fusarium oxysporum f. sp. ciceris on Development of Fusarium Wilt of Chickpea
}

\author{
Juan A. Navas-Cortés, Bernhard Hau, and Rafael M. Jiménez-Díaz
}

First and second authors: Universität Hannover, Institut für Pflanzenkrankheiten und Pflanzenschutz, Herrenhäuser Str. 2, 30419 Hannover, Germany; and third author: Departamento de Agronomía, Universidad de Córdoba, and Instituto de Agricultura Sostenible, Consejo Superior de Investigaciones Científicas (CSIC), Apartado 4084, 14080 Córdoba, Spain.

Current address of J. A. Navas-Cortés: Departamento de Protección de Cultivos, Instituto de Agricultura Sostenible, CSIC. Accepted for publication 14 September 1998.

\begin{abstract}
Navas-Cortés, J. A., Hau, B., and Jiménez-Díaz, R. M. 1998. Effect of sowing date, host cultivar, and race of Fusarium oxysporum f. sp. ciceris on development of Fusarium wilt of chickpea. Phytopathology 88:13381346.

Microplots experiments were carried out at Córdoba, southern Spain, from 1986 to 1989 to determine the effects of sowing date in the management of Fusarium wilt of chickpea as influenced by virulence of the pathogen race and by cultivar susceptibility. A total of 108 epidemics of the disease were described, analyzed, and compared to assess the degree of disease control. The epidemics were characterized by five curve elements: final disease intensity index (DII), standardized area under DII progress curve, time to epidemic onset, time to inflection point $\left(t_{\mathrm{ip}}\right)$, and the DII value at $t_{\mathrm{ip}}$, the last two parameters being estimates from the Richards function adjusted by nonlinear regression analysis. The structure of Fusarium wilt epidemics was examined by conducting multivariate principal components and cluster analyses. From these analyses, three factors accounting

and provided plausible epidemiological interpretations. The first factor included the $t_{\mathrm{ip}}$ and the time to disease onset and can be interpreted as a positional factor over time. This factor accounted for the largest proportion of the total variance and may, therefore, be considered as the main factor for analysis of Fusarium wilt epidemics. The second factor concerns the standardized area under DII progress curves and the final DII of the epidemics. The third factor identified the uniqueness of the estimated value for the point of inflection of the DII progress curve over time. Our results indicate that for each year of experiment epidemic development was related mainly to the date of sowing. Thus, for chickpea crops in southern Spain, advancing the sowing date from early spring to early winter can slow down the development of Fusarium wilt epidemics, delay the epidemic onset, and minimize the final amount of disease. However, the net effect of this disease management practice may also be influenced, though to a lesser extent, by the susceptibility of the chickpea cultivar and the virulence and inoculum density of the Fusarium oxysporum f. sp. ciceris race.
\end{abstract} for 98 to $99 \%$ of the total variance characterized the DII progress curves
Additional keywords: Cicer arietinum, comparative epidemiology.
Chickpea (Cicer arietinum L.) is one of the most important food legumes grown in the Mediterranean Basin and worldwide (39), and it can be a promising alternative crop for rotation with barley, peas, and wheat in dryland areas (3). Fusarium wilt, caused by Fusarium oxysporum Schlechtend.:Fr. f. sp. ciceris (Padwick) Matuo \& K. Sato, is the most important soilborne disease of chickpea throughout the world and particularly in the Indian Subcontinent, the Mediterranean Basin, and California $(16,19,36)$. Attacks by the pathogen can destroy the crop completely $(15,17)$ or cause significant annual yield losses. Annual chickpea yield losses due to Fusarium wilt were estimated at $10 \%$ in India (40) and Spain (42) and $40 \%$ in Tunisia (7). The disease can appear at any stage of plant growth. Symptoms in a highly susceptible cultivar can develop within 25 days after sowing and as late as podding stage. Early wilting causes more loss than late wilting, but seeds from late-wilted plants are lighter, rougher, and duller than those from healthy plants (17).

The most practical and cost-efficient method for management of Fusarium wilt of chickpea is the use of resistant cultivars $(19,35,36)$, the effectiveness of which is curtailed by the occurrence of pathogen races. Haware and Nene (18) first identified races 1, 2, 3, and 4 of $F$. oxysporum f. sp. ciceris in India. Later, three additional races of the pathogen, races 0,5 , and 6, were identified in Andalucía,

Corresponding author: R. M. Jiménez-Díaz; E-mail address: ag1jidir@lucano.uco.es

Publication no. P-1998-1019-03R

(C) 1998 The American Phytopathological Society southern Spain (21). Race 0 isolates induce a progressive foliar yellowing as compared with the severe leaf chlorosis, flaccidity, and early wilt induced by races 1 to 6 (21). Race 0 occurs in California, Spain, and Tunisia; races 1 and 6 were identified in California, Morocco, and Spain; and race 5 has been reported from California and Spain (15,20; R. M. Jiménez-Díaz, unpublished data).

Fusarium wilt of chickpea can also be managed by choice of sowing time $(19,36,38)$. Early work in Andalucía suggested that advancing chickpea sowing from spring to early winter or late fall can reduce incidence of the disease $(42,43)$. However, the adequate assessment of such a crop practice for its effectiveness in the management of Fusarium wilt of chickpea requires a better understanding of the epidemic development of the disease.

The description of a single disease progress curve can give important and useful information about an epidemic. However, a multiple comparison of epidemics is needed for experiments in which different treatments may give rise to a series of plant disease epidemics. The analysis of the characteristics of disease progress curves is an integral part of quantitative epidemiology and can provide valuable information concerning the interrelationships among epidemic components. Yet, the comparison of multiple disease progress curves has, so far, received little attention. Exceptions are in the comparative descriptions of rate curves $(25,27,47)$, in the more widely practiced method of comparisons among slopes of straightline transformations of progress curves $(4,10,44)$, and in the comparison of parameters of nonlinear models for disease progress (12). Nevertheless, the mechanistic comparison of epidemics by uni- 
variate analyses may not necessarily describe the differences among disease progress curves $(10,12,28)$.

A method of multivariate analysis for comparison of entire disease progress curves was initially suggested by Kranz (25). Multivariate analysis serves two purposes; first, it helps to discern the structure in data and, second, it provides an objective summary of the data (11). For satisfactory understanding and comparison of epidemics, it is necessary to know the components that characterize their "core dynamics" (26). Vanderplank (44) identified several important curve elements including the time of disease onset and the rate of disease progression. Kranz (25), in a more complete characterization of plant disease epidemics, specified 13 curve elements for a bilateral disease progress curve. When dissecting epidemics to understand their structure, one should be aware that the behavior of any single component cannot represent the behavior of the entire structure (26). Numerous statistical techniques are available for the analysis of curve elements. Such techniques comprise mathematical methods of classification and ordination that have been widely applied in taxonomy (41), ecology (37), field resistance (2, 29,30), and agricultural science (46) and that could be used to more advantage in plant pathology.

In previous studies (J. A. Navas-Cortés, B. Hau, and R. M. Jiménez-Díaz, unpublished data), we analyzed disease progress over time for 108 epidemics of Fusarium wilt of chickpea developed in a microplot experiment involving different chickpea cultivars, $F$. oxysporum f. sp. ciceris races, inoculum rates, and crop sowing dates. The type of disease progression was determined by fitting the experimental data to the nonlinear forms of the monomolecular, Gompertz, logistic, and Richards models. The relative frequency with which a model provided best fit to data, as well as the Richards model shape parameter, were influenced by the date of sowing and, to a minor extent, by the chickpea cultivars, $F$. oxysporum f. sp. ciceris races, and initial inoculum rates. This paper deals with the multivariate comparison of those epidemics to assess both the degree of control of Fusarium wilt by choice of sowing

TABLE 1. Mean, standard deviation and range values for five curve elements used to characterize epidemics of Fusarium wilt of chickpea caused by Fusarium oxysporum f. sp. ciceris

\begin{tabular}{|c|c|c|c|c|}
\hline $\begin{array}{l}\text { Experimental } \\
\text { period }\end{array}$ & $\begin{array}{l}\text { Curve } \\
\text { element }^{\mathrm{a}}\end{array}$ & Mean & $\begin{array}{l}\text { Standard } \\
\text { deviation }\end{array}$ & Range $^{b}$ \\
\hline \multirow[t]{5}{*}{ Global } & $\mathrm{DII}_{\text {final }}$ & 0.690 & 0.317 & $0.04-1.00$ \\
\hline & SAUDPC & 0.439 & 0.250 & $0.02-0.91$ \\
\hline & $\operatorname{DII}\left(t_{\mathrm{ip}}\right)$ & 0.223 & 0.142 & $0.00-0.58$ \\
\hline & $t_{\text {ip }}$ & 75.912 & 38.412 & $25.51-164.77$ \\
\hline & $t_{0.05}$ & 65.575 & 33.038 & $26.29-144.03$ \\
\hline \multirow[t]{5}{*}{ 1986-1987 } & $\mathrm{DII}_{\text {final }}$ & 0.486 & 0.323 & $0.08-0.94$ \\
\hline & SAUDPC & 0.292 & 0.209 & $0.04-0.68$ \\
\hline & $\operatorname{DII}\left(t_{\mathrm{ip}}\right)$ & 0.153 & 0.142 & $0.00-0.44$ \\
\hline & $t_{\text {ip }}$ & 72.361 & 39.451 & $25.51-164.77$ \\
\hline & $t_{0.05}$ & 58.607 & 24.737 & $26.29-120.41$ \\
\hline \multirow[t]{5}{*}{ 1987-1988 } & $\mathrm{DII}_{\text {final }}$ & 0.599 & 0.379 & $0.04-1.00$ \\
\hline & SAUDPC & 0.395 & 0.310 & $0.02-0.91$ \\
\hline & $\operatorname{DII}\left(t_{\mathrm{ip}}\right)$ & 0.146 & 0.163 & $0.00-0.58$ \\
\hline & $t_{\text {ip }}$ & 80.937 & 45.681 & $27.90-144.57$ \\
\hline & $t_{0.05}$ & 71.687 & 40.172 & $28.13-144.66$ \\
\hline \multirow[t]{5}{*}{ 1988-1989 } & $\mathrm{DII}_{\text {final }}$ & 0.817 & 0.198 & $0.29-1.00$ \\
\hline & SAUDPC & 0.515 & 0.188 & $0.14-0.81$ \\
\hline & $\operatorname{DII}\left(t_{\mathrm{ip}}\right)$ & 0.297 & 0.075 & $0.06-0.38$ \\
\hline & $t_{\text {ip }}$ & 73.838 & 32.980 & $34.25-142.53$ \\
\hline & $t_{0.05}$ & 64.050 & 30.285 & $29.24-120.88$ \\
\hline
\end{tabular}

${ }^{\text {a }} \mathrm{DII}_{\text {final }}=$ disease intensity index determined at the final date of disease assessment; SAUDPC = area under disease intensity progress curve estimated by the trapezoidal integration method standardized by duration time in days; $\mathrm{DII}\left(t_{\mathrm{ip}}\right)=$ disease intensity index at the inflection point of the disease intensity progress curve calculated by the estimates of parameters for the Richards model; $t_{\text {ip }}=$ time in days to reach the point of inflection of the disease intensity progress curve; $t_{0.05}=$ time in days to initial symptoms, estimated as the number of days to reach $\mathrm{DII}=0.05$.

b Based on values obtained from 108 (Global), 18 (1986-1987), 36 (19871988), and 54 (1988-1989) disease progress curves. time and how this disease management practice may be influenced by virulence of pathogen race, cultivar susceptibility, and their interactions.

\section{MATERIALS AND METHODS}

Experimental design. Data used in this study were obtained from a microplot experiment conducted in a field with a sandy loam soil ( $\mathrm{pH} 8.5,1.4 \%$ organic matter) at the Alameda del Obispo Research Station near Córdoba (latitude $38^{\circ}$ north, longitude $5^{\circ}$ east) during three consecutive seasons (harvest years 1987, 1988, and 1989). This field had not been sown to chickpeas during the previous 10 years. The microplots ( 1.25 by $1.25 \mathrm{~m}, 50 \mathrm{~cm}$ deep) were established on a field plot fumigated with methyl bromide + chloropicrin $\left(80 \mathrm{~g} / \mathrm{m}^{2}\right)$ on 30 October 1986. Soil in a microplot was artificially infested with one of three inoculum rates of races 0 and 5 of $F$. oxysporum f. sp. ciceris before sowing in the first year of the experiment on 14 December 1986 (early winter sowing date), 18 February 1987 (late winter sowing date), and 30 March 1987 (early spring sowing date) or maintained as noninfested controls. Chickpea cultivars P-2245 and PV-61 were used. The experimental design consisted of a randomized, single-replicate, split-split plot design, arranged in four blocks. In each season, the treatments comprised all combinations of three levels of date of sowing, two of chickpea cultivars, three of initial inoculum rates of each of the two races of $F$. oxysporum f. sp. ciceris, and one of noninfested control (216 microplots in total).

Times of sowing were 16 December 1986 and 20 February and 2 April 1987 in year 1; 21 December 1987 and 3 February and 21 March 1988 in year 2; and 15 December 1988 and 31 January and 16 March 1989 in year 3. Cultivars P-2245 and PV-61 are kabuli (large, ram-head shape, beige seeds) chickpeas representative of those used in the Mediterranean region. Cultivar P-2245 is highly susceptible to both $F$. oxysporum f. sp. ciceris race 0 (Foc-0) and F. oxysporum f. sp. ciceris race 5 (Foc-5), while 'PV-61' is mod-

TABLE 2. Correlation coefficients ${ }^{\mathrm{a}}$ for five curve elements used to characterize epidemics of Fusarium wilt of chickpea caused by Fusarium oxysporum f. sp. ciceris in different time periods

\begin{tabular}{|c|c|c|c|c|c|c|}
\hline $\begin{array}{l}\text { Experimental } \\
\text { period }\end{array}$ & $\begin{array}{c}\text { Curve } \\
\text { element }^{\mathrm{b}}\end{array}$ & $\mathrm{DII}_{\text {final }}$ & SAUDPC & $\operatorname{DII}\left(t_{\mathrm{ip}}\right)$ & $t_{\text {ip }}$ & $t_{0.05}$ \\
\hline \multirow[t]{5}{*}{ Global } & $\mathrm{DII}_{\text {final }}$ & 1.000 & 0.888 & 0.535 & -0.410 & -0.403 \\
\hline & SAUDPC & $\ldots$ & 1.000 & 0.252 & -0.555 & -0.514 \\
\hline & $\operatorname{DII}\left(t_{\mathrm{ip}}\right)$ & $\ldots$ & $\ldots$ & 1.000 & 0.240 & 0.132 \\
\hline & $t_{\text {ip }}$ & $\ldots$ & $\ldots$ & $\ldots$ & 1.000 & 0.900 \\
\hline & $t_{0.05}$ & $\ldots$ & $\ldots$ & & & 1.000 \\
\hline \multirow[t]{5}{*}{ 1986-1987 } & $\mathrm{DII}_{\text {final }}$ & 1.000 & 0.964 & 0.475 & -0.092 & -0.380 \\
\hline & SAUDPC & $\ldots$ & 1.000 & 0.262 & -0.290 & -0.535 \\
\hline & $\operatorname{DII}\left(t_{\mathrm{ip}}\right)$ & $\cdots$ & $\ldots$ & 1.000 & 0.642 & 0.362 \\
\hline & $t_{\mathrm{ip}}$ & $\ldots$ & $\ldots$ & $\ldots$ & 1.000 & 0.916 \\
\hline & $t_{0.05}$ & $\ldots$ & & & & 1.000 \\
\hline \multirow[t]{5}{*}{ 1987-1988 } & $\mathrm{DII}_{\text {final }}$ & 1.000 & 0.838 & 0.282 & -0.603 & -0.584 \\
\hline & SAUDPC & $\ldots$ & 1.000 & -0.134 & -0.680 & -0.610 \\
\hline & $\operatorname{DII}\left(t_{\mathrm{ip}}\right)$ & $\ldots$ & $\ldots$ & 1.000 & 0.367 & 0.208 \\
\hline & $t_{\mathrm{ip}}$ & $\ldots$ & $\cdots$ & $\cdots$ & 1.000 & 0.845 \\
\hline & $t_{0.05}$ & . & & & & 1.000 \\
\hline \multirow[t]{5}{*}{ 1988-1989 } & $\mathrm{DII}_{\text {final }}$ & 1.000 & 0.918 & 0.749 & -0.425 & -0.333 \\
\hline & SAUDPC & $\ldots$ & 1.000 & 0.604 & -0.597 & -0.513 \\
\hline & $\mathrm{DII}\left(t_{\mathrm{ip}}\right)$ & $\ldots$ & $\ldots$ & 1.000 & -0.026 & -0.006 \\
\hline & $t_{\text {ip }}$ & $\ldots$ & $\ldots$ & $\ldots$ & 1.000 & 0.974 \\
\hline & $t_{0.05}$ & $\ldots$ & $\ldots$ & $\ldots$ & $\ldots$ & 1.000 \\
\hline
\end{tabular}

a Based on values obtained from 108 (Global), 18 (1986-1987), 36 (19871988), and 54 (1988-1989) disease progress curves.

${ }^{\mathrm{b}} \mathrm{DII}_{\mathrm{final}}=$ disease intensity index determined at the final date of disease assessment; SAUDPC = area under disease intensity progress curve estimated by the trapezoidal integration method standardized by duration time in days; $\operatorname{DII}\left(t_{\text {ip }}\right)=$ disease intensity index at the inflection point of the disease intensity progress curve calculated by the estimates of parameters for the Richards model; $t_{\text {ip }}=$ time in days to reach the point of inflection of the disease intensity progress curve; $t_{0.05}=$ time in days to initial symptoms, estimated as the number of days to reach DII $=0.05$. 
erately susceptible to Foc-0 and Foc-5 (21). Seeds were treated with tridemorph (Calixin; BASF Española, S.A., Barcelona, Spain) and captan (Captan 50; Argos, Valencia, Spain) fungicides to eradicate infections by Didymella rabiei (Kovachevsky) von Arx (anamorph Ascochyta rabiei (Pass.) Labrousse) and control Pythium seed rot and preemergence damping-off, respectively $(22,23)$. Each microplot consisted of three rows, $0.4 \mathrm{~m}$ apart and $0.2 \mathrm{~m}$ from the closest microplot edge barrier (25 seeds per row). In year 3 , one additional kabuli chickpea cultivar, PV-60, was used. Cultivar PV-60 is susceptible to both Foc-0 and Foc-5 (21). For the experiment in year 3, each microplot was sown to cultivars P-2245, PV-61, and PV-60, one row each. Weeds in the microplots were removed by hand and dimethoate (Romefos 40; Agrocrós S.A., Madrid, Spain) insecticide was applied to control leaf miner pest (Hylemiya sp.), as needed, according to farmers' practices (13).

F. oxysporum f. sp. ciceris isolates 7802 (race 0) and 8012 (race 5 ) were used. Inoculum was increased in a cornmeal-sand mixture (CMS) (35) incubated at $25^{\circ} \mathrm{C}$ and a 12 -h photoperiod of fluorescent and near-UV light at $36 \mu \mathrm{E} \mathrm{m} \mathrm{m}^{-2} \mathrm{~s}^{-1}$ for 2 weeks. Soil in a microplot was mixed with the infested CMS to establish three rates of inoculum per kilogram of soil in the mixture including $25.0 \mathrm{~g}$ (low), $50.0 \mathrm{~g}$ (intermediate), or $100.0 \mathrm{~g}$ (high) for Foc-0; and $6.25 \mathrm{~g}$ (low), $12.5 \mathrm{~g}$ (intermediate), or $25.0 \mathrm{~g}$ (high) for Foc-5. Similar rates of noninfested CMS were used for microplots that served as

TABLE 3. Eigenvectors and eigenvalues ${ }^{\mathrm{a}}$ of principal components derived from five curve elements used to characterize epidemics of Fusarium wilt of chickpea caused by Fusarium oxysporum f. sp. ciceris in three time periods

\begin{tabular}{|c|c|c|c|c|c|c|c|c|c|c|c|c|}
\hline \multirow[b]{3}{*}{ Element $^{\mathrm{b}}$} & \multicolumn{12}{|c|}{ Experimental period } \\
\hline & \multicolumn{3}{|c|}{ Global } & \multicolumn{3}{|c|}{ 1986-1987 } & \multicolumn{3}{|c|}{ 1987-1988 } & \multicolumn{3}{|c|}{ 1988-1989 } \\
\hline & $\mathrm{F} 1$ & F2 & F3 & $\mathrm{F} 1$ & $\mathrm{~F} 2$ & F3 & $\mathrm{F} 1$ & F2 & F3 & $\mathrm{F} 1$ & $\mathrm{~F} 2$ & F3 \\
\hline SAUDPC & -0.34 & $0.92 *$ & 0.08 & -0.25 & $0.96^{*}$ & 0.08 & -0.37 & $0.91 *$ & -0.13 & -0.38 & $0.87 *$ & 0.28 \\
\hline $\operatorname{DII}\left(t_{\mathrm{ip}}\right)$ & 0.14 & 0.23 & $0.96^{*}$ & 0.37 & 0.29 & $0.88^{*}$ & 0.14 & 0.04 & $0.98^{*}$ & 0.07 & 0.43 & $0.90 *$ \\
\hline$t_{\text {ip }}$ & $0.93 *$ & -0.28 & 0.18 & $0.91 *$ & -0.09 & 0.38 & $0.90 *$ & -0.34 & 0.26 & $0.95^{*}$ & -0.29 & 0.03 \\
\hline$t_{0.05}$ & $0.95 *$ & -0.27 & -0.01 & $0.93 *$ & -0.32 & 0.12 & $0.89^{*}$ & -0.44 & 0.02 & $0.98^{*}$ & -0.16 & -0.01 \\
\hline Variance & 1.98 & 1.80 & 1.13 & 1.92 & 2.03 & 1.01 & 1.97 & 1.80 & 1.17 & 2.06 & 1.77 & 1.09 \\
\hline Cum. expl. var. (\%) & 59.3 & 89.8 & 98.1 & 52.4 & 94.0 & 99.3 & 66.0 & 90.8 & 98.7 & 62.6 & 93.6 & 98.6 \\
\hline
\end{tabular}

a Curve element based on values obtained from 108 (Global), 18 (1986-1987), 36 (1987-1988), and 54 (1988-1989) disease progress curves.

${ }^{\mathrm{b}} \mathrm{DII}_{\text {final }}=$ disease intensity index determined at the final date of disease assessment; SAUDPC $=$ area under disease intensity progress curve estimated by the trapezoidal integration method standardized by duration time in days; DII $\left(t_{\mathrm{ip}}\right)=$ disease intensity index at the inflection point of the disease intensity progress curve calculated by the estimates of parameters for the Richards model; $t_{\mathrm{ip}}=$ time in days to reach the point of inflection of the disease intensity progress curve; $t_{0.05}$ $=$ time in days to initial symptoms, estimated as the number of days to reach DII $=0.05$. Cum. expl. var. $(\%)=$ percent cumulative explained variance.

$\mathrm{c} *$ = Values of curve elements dominating principal components F1, F2, and F3.

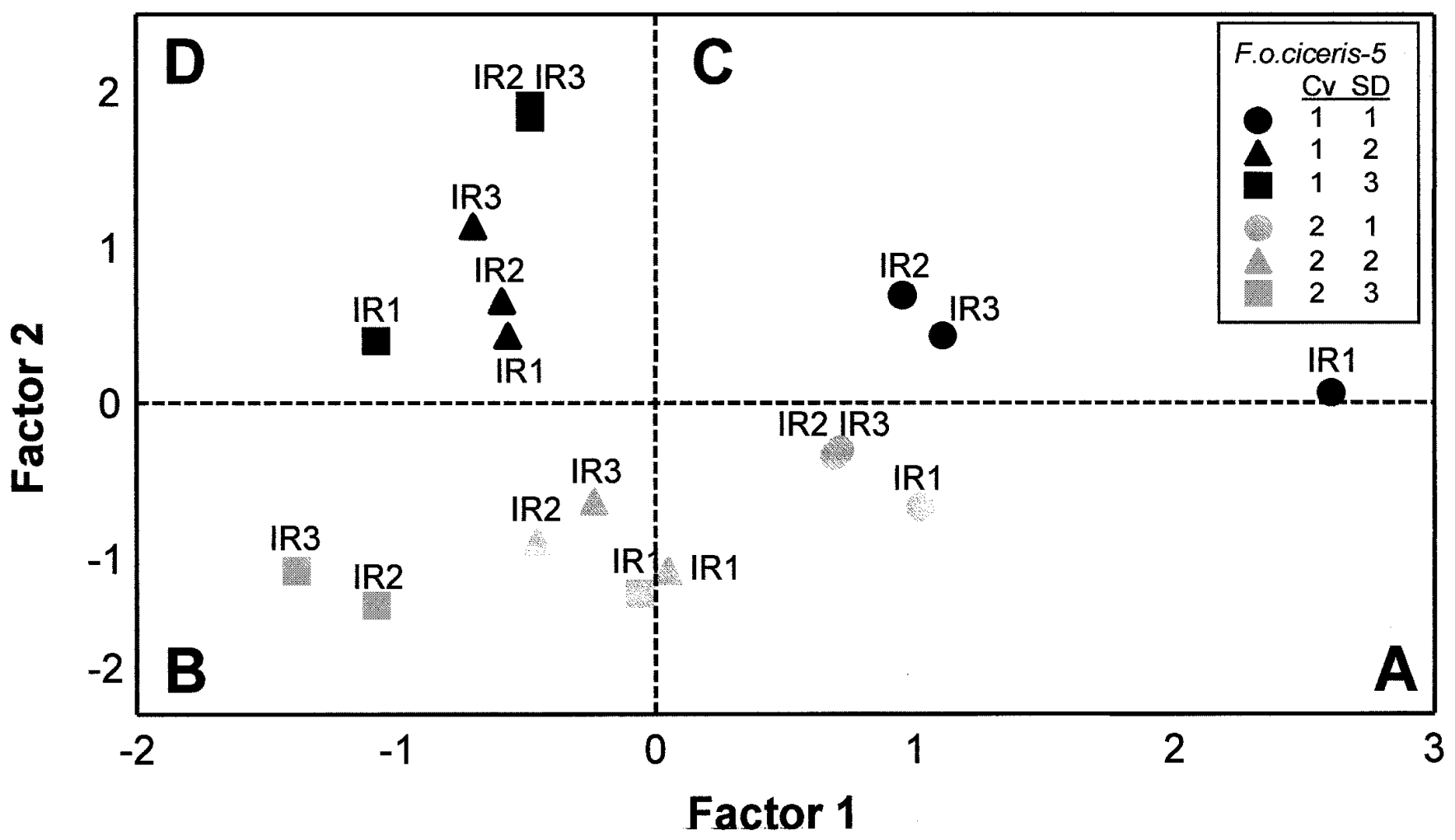

Fig. 1. Projection of factor scores on the plane of factors 1 and 2 from principal component analysis for the time period 1986 to 1987. Chickpea cultivars P-2245 (cv. 1) or PV-61 (cv. 2) were sown in microplots artificially infested with Fusarium oxysporum f. sp. ciceris race 5 on 16 December 1986 (SD1), 20 February 1987 (SD2), and 2 April 1987 (SD3). The infested substrate was mixed thoroughly with the upper 15-cm layer of fumigated soil at an inoculum rate of $6.25 \mathrm{~g}$ (IR1), $12.5 \mathrm{~g}$ (IR2), or $25.0 \mathrm{~g}$ (IR3) per kilogram of soil. According to position of projected epidemics along the $\mathrm{X}$ axis, epidemic development is delayed from left to right. Similarly, position of projected epidemics along the $\mathrm{Y}$ axis indicates that the overall disease intensity increases from bottom to top along the axis. Disease intensity of an epidemic increases progressively from $\mathbf{A}$ to $\mathbf{D}$. A, Epidemics with the least disease intensity and the most delayed disease onset. D, Epidemics with the highest disease intensity and earliest disease onset. 
controls. Inoculum density of $F$. oxysporum in the infested soil mixture was determined by dilution-plating on V8 juice-oxgall-pentachloronitrobenzene agar (VOPA) Fusarium-selective medium (6) each year prior to sowing. Soil samples were collected with a shovel to a depth of $15 \mathrm{~cm}$ from each microplot, bulked, thoroughly mixed, and used for dilution-plating. Different dilution factors were used depending on inoculum rate and race of the pathogen. A 1-g airdried sample of soil was placed into a vessel containing $100 \mathrm{ml}$ of sterile $0.1 \%$ water agar and stirred in a blender for $1 \mathrm{~min}$. This suspension $(1 \mathrm{ml})$ was spread onto each of four plates of VOPA. Plates were incubated under the same conditions as inoculum for 7 days. Colonies of Fusarium that grew on the selective medium were identified as $F$. oxysporum based on the presence of short monophialides bearing microconidia in false heads, chlamydospores, and characteristically shaped macroconidia.

Disease reactions were assessed by the incidence and severity of symptoms at 7- to 10-day intervals. Severity of symptoms in individual plants of a microplot was assessed on a 0 to 4 rating scale according to percentage of foliage with yellowing or necrosis in acropetal progression $(0=0 \%, 1=1$ to $33 \%, 2=34$ to $66 \%, 3=67$ to $100 \%$, and $4=$ dead plant). Incidence of foliar symptoms, $I$, (in a 0 to 1 scale) and severity data, $S$, (categorized from 0 to 4 ) were used to calculate a disease intensity index (DII) (1) by the equation DII = $(I \times S) / 4$. Thus, DII expresses the mean value of disease intensity at any given moment as a proportion of the maximum possible amount of disease. Disease progress curves were obtained from the accumulated DII over time in days from the date of sowing.

Curve elements. The 108 disease progress curves were characterized by means of the five associated variables: (i) final disease intensity $\left(\mathrm{DII}_{\text {final }}\right)=$ DII observed at the final date of disease assessment; (ii) the standardized area under disease progress curve
(SAUDPC) calculated by the trapezoidal integration method standardized by duration time in days (8); (iii) $\operatorname{DII}\left(t_{\mathrm{ip}}\right)=$ the DII level at the time when the curve reached the point of inflection; (iv) $t_{\text {ip }}=$ the time needed to reach the point of inflection; and (v) $t_{0.05}=$ the time in days to initial symptoms, estimated as the number of days to reach a DII level of 0.05 . The inflection point and time needed to reach it were obtained by the estimates of parameters of the Richards model fitted to the entire set of DII progress data using nonlinear regression analysis (J. A. Navas-Cortés, B. Hau, and R. M. Jiménez-Díaz, unpublished data). The Richards model can be written as DII $=K[1-B \exp (-r t)]^{1 /(1-m)}$ when $m<1$ and DII $=K[1+$ $B \exp (-r t)]^{1 /(1-m)}$ when $m>1$, in which DII = disease intensity index, $K=$ asymptote parameter, $B=$ constant of integration, $r=$ rate parameter, $m=$ shape parameter, and $t=$ time of disease assessment in days after the date of sowing. For this model, the disease level at the inflection point (DII $\left.\left[t_{\text {ip }}\right]\right)$ occurs at $\operatorname{DII}\left(t_{\text {ip }}\right)=K m^{1 /(1-m)}$, and the time to reach this level $\left(t_{\text {ip }}\right)$ is given $(31)$ by $t_{\text {ip }}=[\ln (B)-$ $\ln (1-m)] r^{-1}$ when $m<1$ and $t_{\text {ip }}=[\ln (B)-\ln (m-1)] r^{-1}$ when $m>1$.

Principal component analysis was performed with the SAS FACTOR procedure (version 6.11; SAS Institute Inc., Cary, NC). This analysis produced a set of variables that were linear combinations of the original variables. The new variables were independent of each other and ranked according to the amount of variation accounted for. After the initial factor extraction, an orthogonal varimax rotation was used to estimate the factor loadings.

Additionally, an hierarchical cluster analysis was performed using Euclidean distance between experimental treatments as defined by the average of the multiple variables. The Ward's method was used in the SAS CLUSTER procedure (version 6.11; SAS Institute Inc.). The first three factors associated with the five curve elements mentioned above were used to characterize each epidemic.

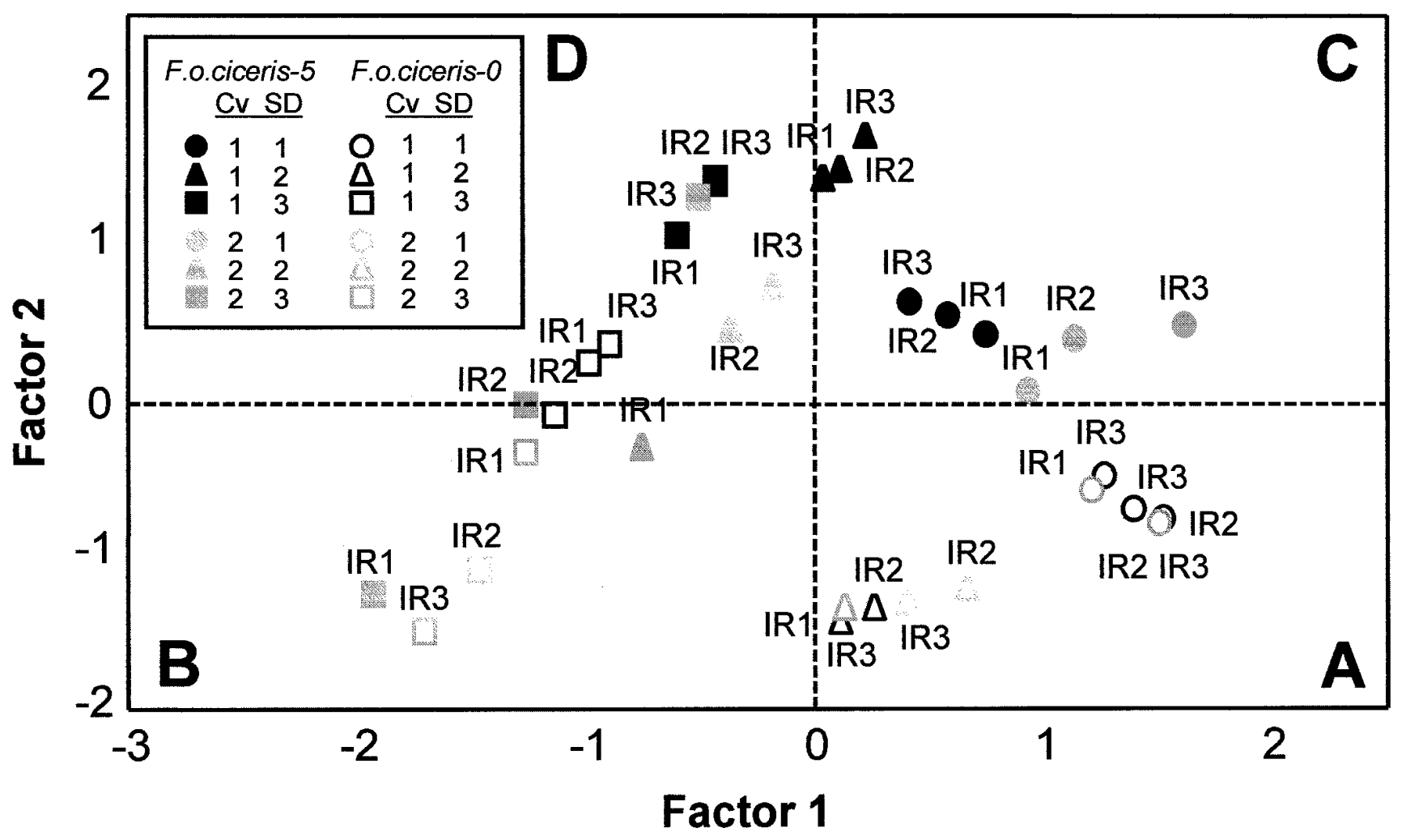

Fig. 2. Projection of factor scores on the plane of factors 1 and 2 from principal component analysis for the time period 1987 to 1988 . Chickpea cultivars P2245 (cv. 1) or PV-61 (cv. 2) were sown in microplots artificially infested with Fusarium oxysporum f. sp. ciceris race 0 (Foc-0) or race 5 (Foc-5) on 21 December 1987 (SD1), 3 February 1998 (SD2), and 21 March 1988 (SD3). The infested substrate was mixed thoroughly with the upper 15-cm layer of fumigated soil at an inoculum rate of $25.0 \mathrm{~g}$ (IR1), $50.0 \mathrm{~g}$ (IR2), or $100 \mathrm{~g}$ (IR3) per kilogram of soil for Foc-0; and $6.25 \mathrm{~g}$ (IR1), $12.5 \mathrm{~g}$ (IR2), or 25.0 g (IR3) per kilogram of soil for Foc-5. According to position of projected epidemics along the X axis, epidemic development is delayed from left to right. Similarly, position of projected epidemics along the $\mathrm{Y}$ axis indicates that the overall disease intensity increases from bottom to top along the axis. Disease intensity of an epidemic increases progressively from $\mathbf{A}$ to $\mathbf{D}$. A, Epidemics with the least disease intensity and the most delayed disease onset. D, Epidemics with the highest disease intensity and earliest disease onset. 


\section{RESULTS}

Factor analysis. Means, standard deviations, and ranges for the five curve elements used in the factor analysis are listed in Table 1. The correlation coefficients among those variables are presented in Table 2. Relatively high correlations were detected among some of the five curve elements used to characterize epidemics of Fusarium wilt of chickpea (Table 2). DII final $_{\text {and SAUDPC }(r>0.83)}$ as well as $t_{\text {ip }}$ and $t_{0.05}(r>0.84)$ were the curves elements with the highest correlation coefficients (Table 2 ).

In the factor analysis, the first three factors accounted for at least $98 \%$ of the total variance when the 108 epidemics were used in a single analysis, as well as when the epidemics of a single season were considered separately (Table 3 ). Variation accounted for by factors 4 and 5 was marginal; therefore, only the first three factors were extracted from the disease progress data. As a result, the dimensionality of the curve elements was effectively reduced to three descriptive variables. Table 3 includes the eigenvalues for the factors extracted. Factors were a combination of all curve elements in the analysis, and the corresponding values in the eigenvectors for each curve element were used to interpret the epidemiological significance of the factors. Factor 1 is dominated by high positive weights $(>0.89)$ for $t_{\text {ip }}$ and $t_{0.05}$ and, to a lesser extent, by smaller positive weight for $\operatorname{DII}\left(t_{\text {ip }}\right)$ and smaller negative weights for $\mathrm{DII}_{\text {final }}$ and SAUDPC. This factor can be interpreted as a positional factor for the epidemic development over time. Factor 2 is dominated by high positive weights for $\mathrm{DII}_{\text {final }}$ and SAUDPC and, to lesser extent, by positive weights for the $\operatorname{DII}\left(t_{\text {ip }}\right)$ and negative weights for the $t_{\text {ip }}$ and the $t_{0.05}$. Thus, factor 2 represents the amount of disease developed during epidemics. Factor 3, which accounts for the lowest percentage of the cumulative explained variance $(<9 \%)$, identifies the uniqueness of the $\operatorname{DII}\left(t_{\text {ip }}\right)$ with respect to the other curve elements, and it represents the shape of the disease progress curve.

Figures 1 to 3 are biplot displays representing Fusarium wilt epidemics developed during each year of experiment, respectively, projected on the plane of factors 1 and 2. Factors 1 and 2 are negatively and positively correlated with disease intensity, respectively. According to position of projected epidemics along the $\mathrm{X}$ axis, epidemic development is delayed from left to right. Similarly, position of projected epidemics along the $\mathrm{Y}$ axis indicates that the overall disease intensity increases from bottom to top along the axis. Thus, epidemics with the least disease intensity and the most delayed disease onset are grouped at the bottom right quadrant (A), and those with the highest disease intensity and earliest disease onset are located on the top left quadrant (D). Therefore, disease intensity of an epidemic increases progressively from epidemics projected on quadrant $\mathrm{A}$ to those projected on quadrants $\mathrm{B}, \mathrm{C}$, and $\mathrm{D}$, in this sequence (Figs. 1 to 3 ).

For the 3 years of experiments, epidemics are located along the $\mathrm{X}$ axis according to time of sowing (i.e., those developed on early winter sowings are located in the far right side, while those occurring on late winter or early spring sowings are placed in the middle or at the far-left side of the X axis). Therefore, under the Mediterranean environment prevailing in Andalucía, southern Spain, advancing chickpea sowing from early spring to early winter contributes significantly to delay disease onset and reduce the final amount of disease. On the other hand, location of projected epidemics along the $\mathrm{Y}$ axis is influenced by combinations of chickpea cultivars and pathogen races. In 1986 to 1987, no disease developed in microplots infested with the least virulent pathogen race (Foc-0) and,

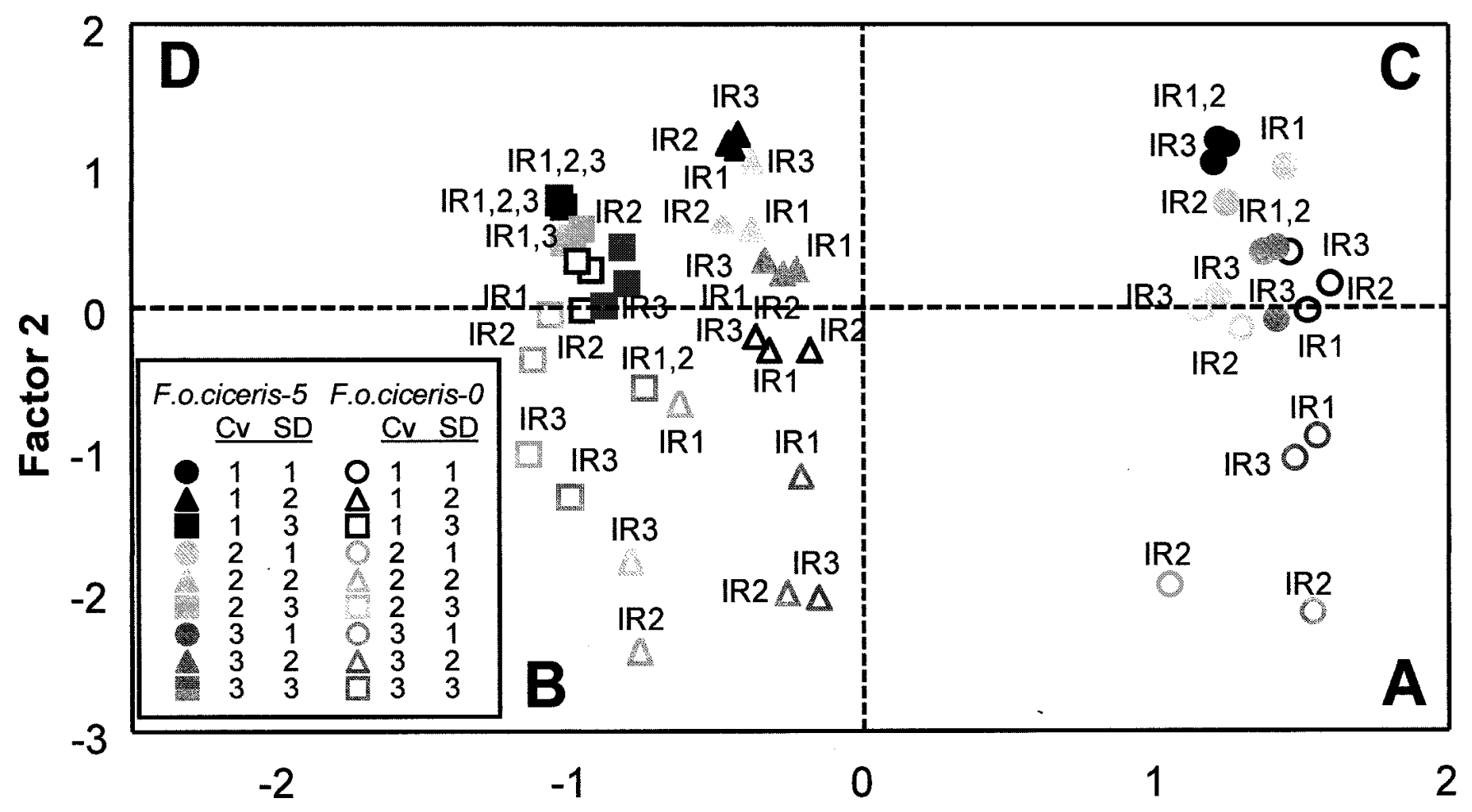

Factor 1

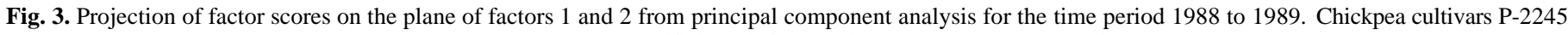

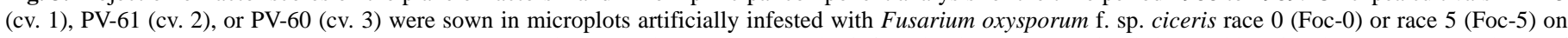

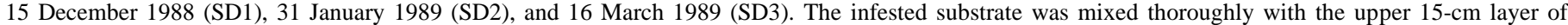

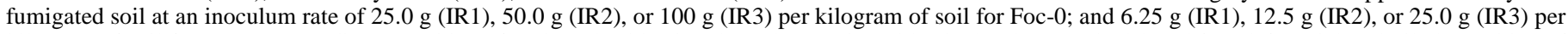

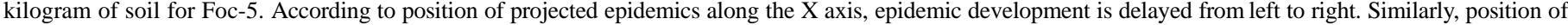

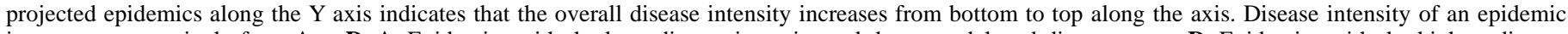

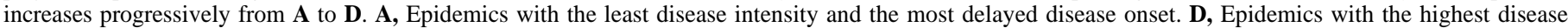
intensity and earliest disease onset. 


\section{Treatment}

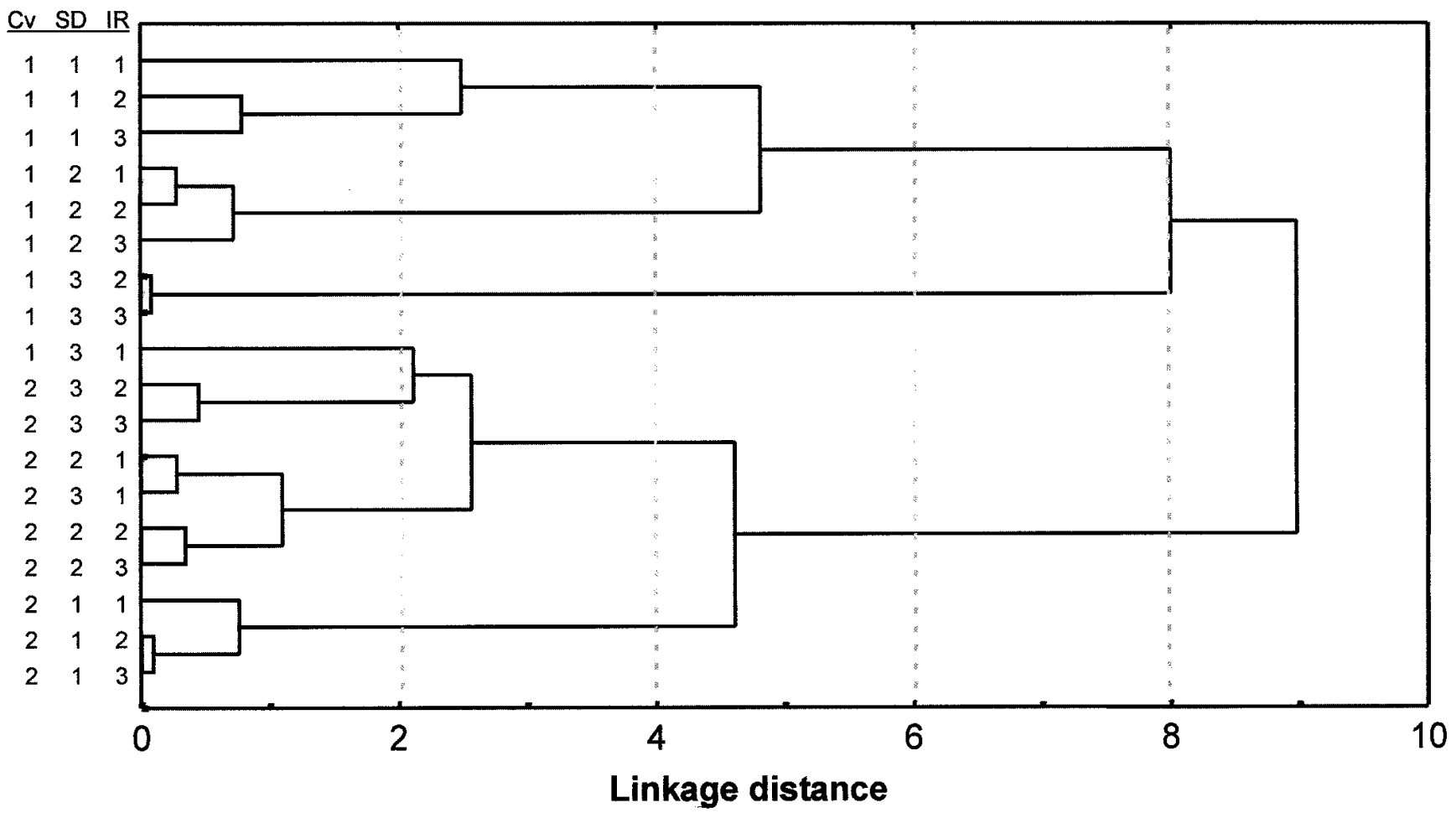

Fig. 4. Dendrogram representing relative similarities among 18 Fusarium wilt epidemics for the time period 1986 to 1987. Chickpea cultivars P-2245 (cv. 1) or PV-61 (cv. 2) were sown in microplots artificially infested with Fusarium oxysporum f. sp. ciceris race 5 on 16 December 1986 (SD1), 20 February 1987 (SD2), and 2 April 1987 (SD3). The infested substrate was mixed thoroughly with the upper 15-cm layer of fumigated soil at an inoculum rate of $6.25 \mathrm{~g}$ (IR1), $12.5 \mathrm{~g}$ (IR2), or $25.0 \mathrm{~g}$ (IR3) per kilogram of soil.

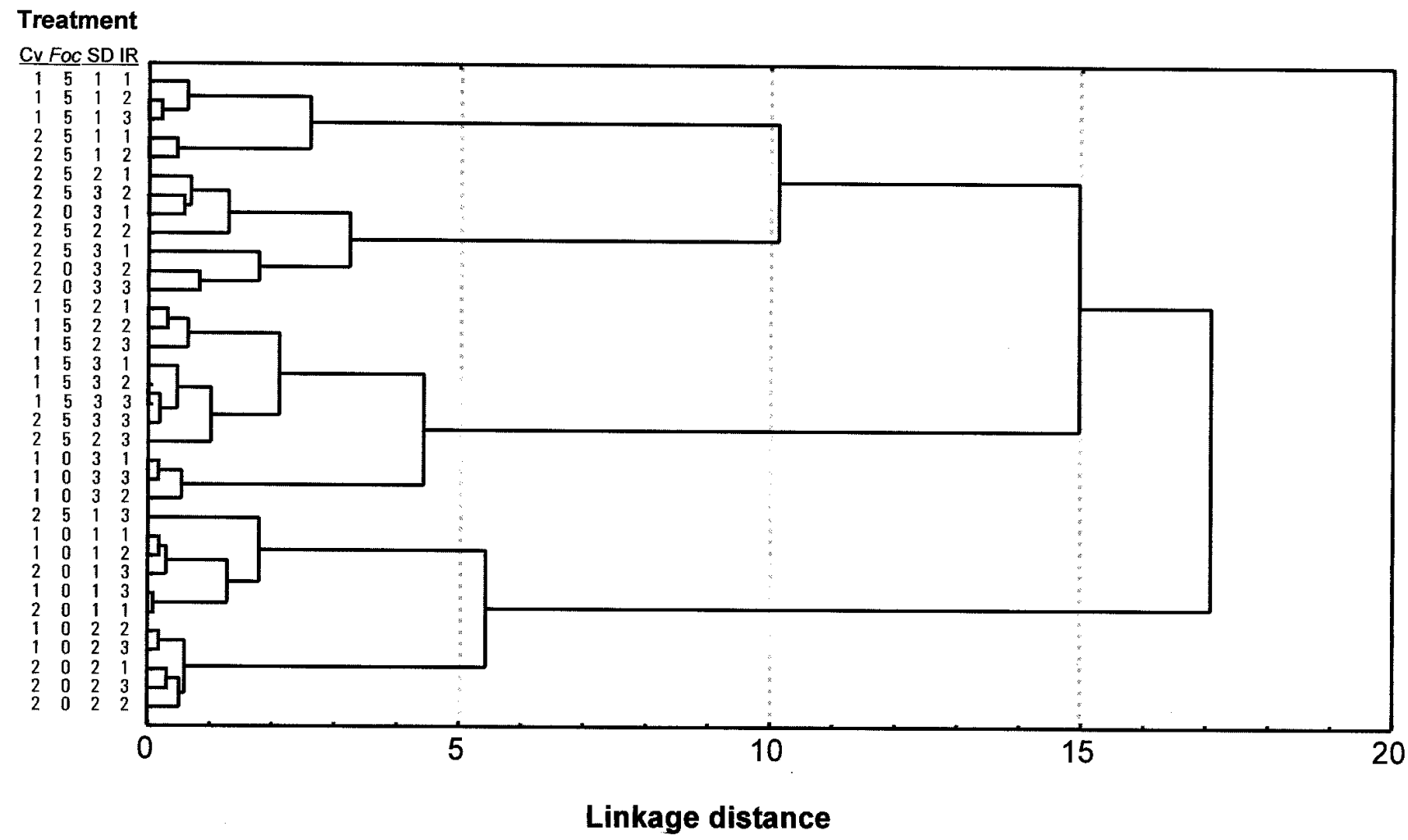

Fig. 5. Dendrogram representing relative similarities among 36 Fusarium wilt epidemics for the time period 1987 to 1988 . Chickpea cultivars P-2245 (cv. 1) or PV-61 (cv. 2) were sown in microplots artificially infested with Fusarium oxysporum f. sp. ciceris race 0 (Foc-0) or race 5 (Foc-5) on 21 December 1987 (SD1), 3 February 1988 (SD2), and 21 March 1988 (SD3). The infested substrate was mixed thoroughly with the upper 15-cm layer of fumigated soil at an inoculum rate of $25.0 \mathrm{~g}$ (IR1), $50.0 \mathrm{~g}$ (IR2), or $100 \mathrm{~g}$ (IR3) per kilogram of soil for Foc-0; and $6.25 \mathrm{~g}$ (IR1), $12.5 \mathrm{~g}$ (IR2), or $25.0 \mathrm{~g}$ (IR3) per kilogram of soil for Foc-5. 
therefore, only data for the highly virulent pathogen race (Foc-5) were available. In this season, epidemics developed on 'PV-61' (moderately susceptible) are located below Y $=0$ (Fig. 1), indicating less disease as compared with that developed on 'P-2245' (highly susceptible) for which epidemics are located above $\mathrm{Y}=0$ (Fig. 1). With few exceptions in the 1987 to 1988 and 1988 to 1989 experiments, epidemics that developed in microplots infested with Foc- 0 are located below $\mathrm{Y}=0$, while those epidemics caused by Foc-5 are located above $Y=0$, irrespective of the chickpea cultivar (Figs. 2 and 3). Thus, the net effects of advancing chickpea sowing on control of Fusarium wilt depends upon the susceptibility of the cultivar and virulence of the $F$. oxysporum $\mathrm{f}$. $\mathrm{sp}$. ciceris race (i.e., the overall benefit for disease management that results from early sowing diminishes if a highly susceptible cultivar is used, a highly virulent race prevails in soil, or both).

Cluster analysis. Epidemics of Fusarium wilt were widely distributed in the cluster analysis and tree diagram (Figs. 4 to 6). Epidemics connected at short linkage distances from the base had similar measures of disease elements.

In the 1986 to 1987 experiment, two first-order clusters comprise epidemics that occurred on 'P-2245' and 'PV-61'. For each of these cultivars, minor-order clusters are formed by epidemics that developed for each of the three sowing dates (Fig. 4). In the 1987 to 1988 experiment, first-order clusters include epidemics that developed in microplots infested with either Foc-0 or Foc-5 (Fig. 5). Progressive minor-order clusters include epidemics that developed on 'P-2245' and 'PV-61', irrespective of the sowing date. In 1988 to 1989 , main clusters group epidemics that developed in microplots sown at either of the three sowing dates. Consecutively lowerorder clusters comprise those epidemics that occurred in microplots infested with different rates of inoculum of Foc- 0 or Foc-5 and sown to the three chickpea cultivars in the 1988 to 1989 experiment (Fig. 6). The lowest-order cluster grouped epidemics differing in initial inoculum rate. This was true irrespective of sowing date, F. oxysporum f. sp. ciceris race, and chickpea cultivar used throughout the 3-year study (Figs. 4 to 6).

\section{DISCUSSION}

Fusarium wilt of chickpea can be managed by choice of sowing date $(19,38,43)$. However, both the epidemic development and description associated with such a disease management practice may be influenced by a number of factors, thus making it difficult to assess its effect in disease control (J. A. Navas-Cortés, B. Hau, and R. M. Jiménez-Díaz, unpublished data). The aim of this work was to assess the effects of sowing date for the management of Fusarium wilt of chickpea by means of the multivariate comparison of 108 epidemics developed in 3 years of microplot experiments. These experiments included a number of combinations of pathogen races and host cultivars.

The amount of Fusarium wilt recorded in 3 years varied considerably, possibly because of differences in weather conditions and the increase of the pathogen population in soil as a result of disease in successive chickpea sowings (J. A. Navas-Cortés, B. Hau, and R. M. Jiménez-Díaz, unpublished data). However, such a variation did not influence the usefulness of multivariate analysis for our study. For each year of experiment, changes in characteristics of disease progression were related mainly to date of sowing, cultivar susceptibility, virulence of the pathogen race, and their interactions (J. A. Navas-Cortés, B. Hau, and R. M. Jiménez-Díaz, unpublished data). Also, for each chickpea cultivar-pathogen race combination, differences among epidemics associated with the three sowing dates could be attributed to differences in rainfall and temperature. In southern Spain, delaying the date of sowing from midDecember to mid-March allows for a decrease of residual soil moisture and an increase of temperature, thus favoring development of

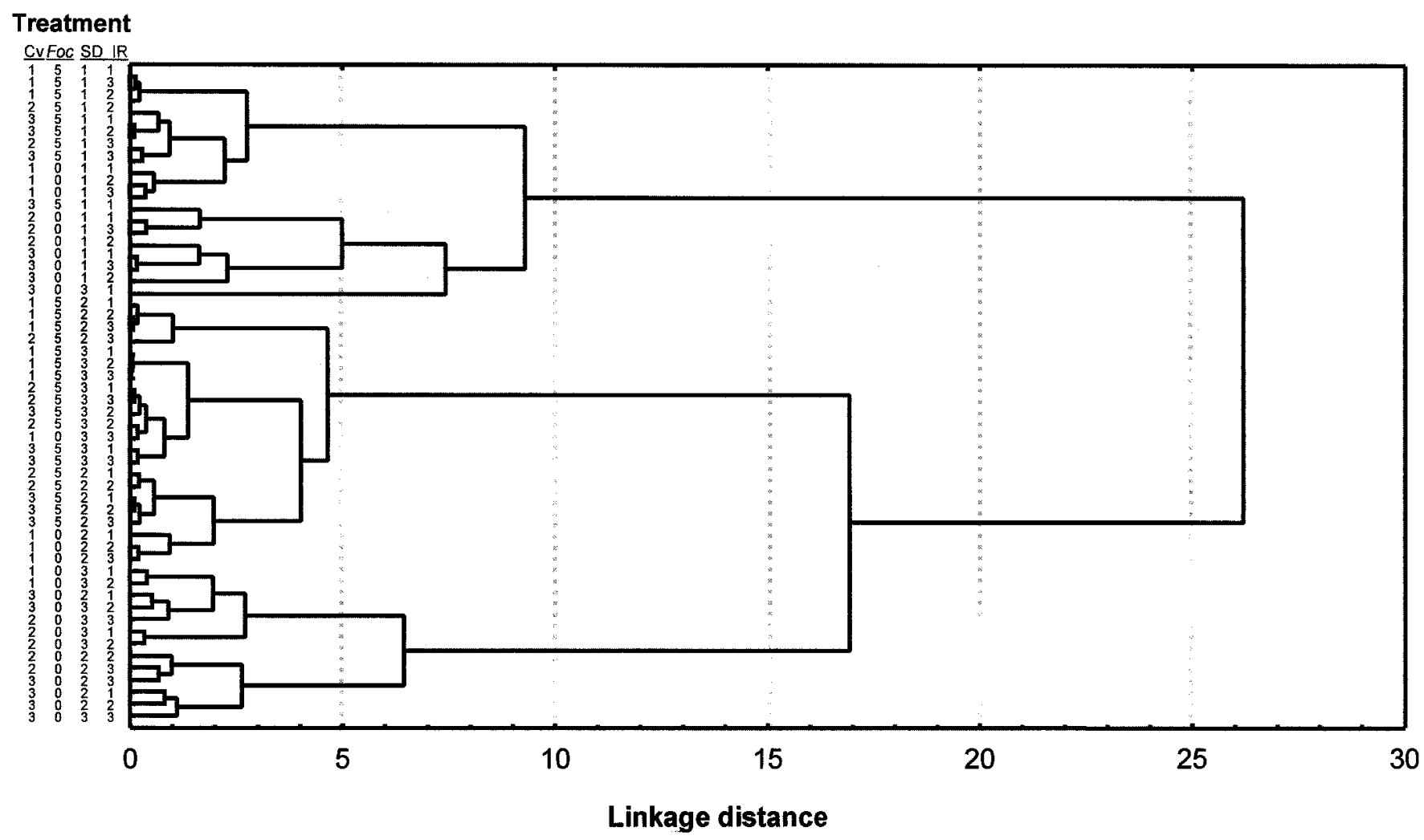

Fig. 6. Dendrogram representing relative similarities among 54 Fusarium wilt epidemics for the time period 1988 to 1989. Chickpea cultivars P-2245 (cv. 1), PV-61 (cv. 2), or PV-60 (cv. 3) were sown in microplots artificially infested with Fusarium oxysporum f. sp. ciceris race 0 (Foc-0) or race 5 (Foc-5) on 15 December 1988 (SD1), 31 January 1989 (SD2), and 16 March 1989 (SD3). The infested substrate was mixed thoroughly with the upper 15-cm layer of fumigated soil at an inoculum rate of $25.0 \mathrm{~g}$ (IR1), $50.0 \mathrm{~g}$ (IR2), or $100 \mathrm{~g}$ (IR3) per kilogram of soil for Foc-0; and 6.25 g (IR1), $12.5 \mathrm{~g}$ (IR2), or 25.0 g (IR3) per kilogram of soil for Foc-5. 
Fusarium wilt. This is supported by observations in India (14) and California (45) for which annual variation in the severity of Fusarium wilt was attributed to differences in temperature and inoculum density of F. oxysporum f. sp. ciceris in soil. In laboratory studies, severity of wilt was also positively correlated with increasing soil temperature and inoculum density of the pathogen $(5,34)$. Results similar to ours were obtained in experiments conducted in India over four seasons in which Fusarium wilt incidence decreased and seed yield increased as chickpea sowing was delayed up to midOctober (38).

In our research, the structure of the 108 Fusarium wilt epidemics studied was determined by conducting a combination of principal component and cluster analyses. This resulted in an epidemic being characterized by five curve elements. Two curve elements, DII $_{\text {final }}$ and the SAUDPC, were complemented with three additional elements: $\operatorname{DII}\left(t_{\mathrm{ip}}\right), t_{\mathrm{ip}}$, and $t_{0.05}$, calculated using the estimated parameter values of the Richards model fitted to disease progress data. These five selected disease progress curve elements were reduced to three unobservable factors that could be interpreted epidemiologically.

The first factor was interpreted as a positional factor including $t_{\text {ip }}$ and $t_{0.05}$. This is similar to results from Campbell et al. (9) who described each of 100 bean root rot epidemics induced by Rhizoctonia solani with eight curve elements. By means of principal factor analysis, they extracted four factors that accounted for $90 \%$ of the total variance. The third factor was established as an epidemic location factor identified by the estimated time to disease onset. In our study, this factor accounted for the largest proportion of the total variance and was considered the main factor in distinguishing epidemics of Fusarium wilt on chickpeas.

The second factor in our study is related to DII final $_{\text {and }}$ SAUDPC. The evidence of such a relationship was strengthened by several authors previously. Kranz (24) characterized 80 disease progress curves of different pathosystems by means of factor analysis and determined six factors using 10 curve elements. The first factor represented disease level because of high factor loadings assigned to disease incidence as well as to area under disease progress curves (AUDPC). While determining the structure of bean root rot epidemics, Campbell et al. (9) identified a second factor related to AUDPC and final disease levels. Similarly, Madden and Pennypacker (32) used principal component analysis to characterize the structure of 18 tomato early blight epidemics induced by Alternaria solani and found that the first component, explaining $84 \%$ of the total variance, was the major factor distinguishing these curves by their overall level or height. A third factor in our study specified the uniqueness of the estimated value for the point of inflection and is, therefore, closely related to the shape of the disease progress curve. A principal component representing variation in shape or skewness from the mean disease progress curve was also estimated for tomato early blight epidemics (32).

The potential problem of collinearity, or existence of highly correlated variables within data sets, was stressed by Mora-Aguilera et al. (33). They investigated a set of variables with the disease progress curve for problems of collinearity through principal component analysis. In their work, the effect of cultural practices on the selected variables was studied by classifying the epidemics via cluster analysis. By using nine epidemiological parameters including some of the curve elements suggested by Kranz (25) and complemented with the scale and shape parameters of the Weibull model, Mora-Aguilera et al. (33) selected three curve elements, the SAUDPC, the shape parameter of the Weibull distribution function, and the time between dates of transplanting and appearance of first symptoms as the variables with the highest explanatory capacity.

However, the relative importance and association among factors and curve elements largely depended on the curve elements and the statistical procedures used to describe disease progression. Therefore, in general, similar plausible epidemiological interpretations could be assigned to factors extracted from a given set of curve elements.
Combining principal components and cluster analyses allowed us to compare 108 epidemics of Fusarium wilt and assess the effect of chickpea sowing date for disease management as influenced by cultivar susceptibility and pathogen virulence. Thus, such a combined analysis facilitated overcoming difficulties in the comparison of epidemics as a result of the extreme complexity for their appropriate description (J. A. Navas-Cortés, B. Hau, and R. M. Jiménez-Díaz, unpublished data). Under conditions in southern Spain, advancing chickpea sowing from early spring to early winter significantly delays epidemic onset, slows down epidemic development, and reduces the final amount of disease, and consequently the loss of seed yield caused by Fusarium wilt (J. A. Navas-Cortés and R. M. Jiménez-Díaz, unpublished data). However, the benefits provided by such a measure for Fusarium wilt management can be overridden if practiced with a cultivar too susceptible to the disease, in soils where a highly virulent race of the pathogen prevails, or both. This emphasizes the usefulness of chickpea cultivars with a late-wilting (slow-wilting) disease reaction, as well as of efficient tools for the diagnosis and assessment of inoculum of the pathogen race in soil, for implementing of sowing date as a management practice of Fusarium wilt of chickpea.

\section{ACKNOWLEDGMENTS}

Research support was provided by a postdoctoral fellowship for J. A. Navas-Cortés from CSIC, Spain, and by grants AGR89-0533-C02-01 from Comisión Interministerial de Ciencia y Tecnología (CICYT) of Spain and CCHN 8510/030 from the Spanish-USA Joint Committee for Scientific and Technological Cooperation.

\section{LITERATURE CITED}

1. Acimovic, M. 1979. Evaluation procedures for the intensity of disease occurrence in sunflower. Helia 2:55-57.

2. Anderson, W. F., Beute, M. K., Wynne, J. C., and Wongkaew, S. 1990. Statistical procedures for assessment of resistance in a multiple foliar disease complex of peanut. Phytopathology 80:1451-1459.

3. Auld, D. L., and Lee, C. A. 1981. Chickpeas: A potential new pulse for northern Idaho. Univ. Idaho Coop. Ext. Serv. Curr. Inf. Ser. 570.

4. Berger, R. D. 1988. The analysis of effects of control measures on the development of epidemics. Pages 137-151 in: Experimental Techniques in Plant Disease Epidemiology. J. Kranz and J. Rotem, eds. SpringerVerlag KG, Berlin.

5. Bhatti, M. A., and Kraft, J. M. 1992. Effects of inoculum density and temperature on root rot and wilt of chickpea. Plant Dis. 76:50-54.

6. Bouhot, D., and Rouxel, F. 1971. Technique sélective et quantitative d'analyse des Fusarium oxysporum et Fusarium solani dans le sol. Mode d'emploi. Ann. Phytopathol. 3:251-254.

7. Bouslama, M. 1980. Chickpea improvement in Tunisia. Pages 277-280 in: Proc. Int. Workshop Chickpea Improvement. International Crops Research Institute for the Semi-Arid Tropics (ICRISAT), Patancheru, India.

8. Campbell, C. L., and Madden, L. V. 1990. Introduction to Plant Disease Epidemiology. John Wiley \& Sons, New York.

9. Campbell, C. L., Madden, L. V., and Pennypacker, S. P. 1980. Structural characterization of bean root rot epidemics. Phytopathology 70:152-155.

10. Fulton, W. C. 1979. On comparing values of Vanderplank's $r$. Phytopathology 69:1162-1164.

11. Gauch, H. G. 1982. Multivariate Analysis in Community Ecology. (Cambridge studies in ecology, 1.) Cambridge University Press, Cambridge.

12. Gilligan, C. A. 1990. Comparison of disease progress curves. New Phytol. 115:223-242.

13. Guerrero, A. 1990. Garbanzos. Pages 504-514 in: Cultivos Herbáceos Extensivos. A. Guerrero, ed. Ediciones Mundi-Prensa, Madrid.

14. Gupta, O., Kotasthane, S. R., and Khare, M. N. 1987. Factors influencing epidemiology of vascular wilt of chickpea. Proc. Natl. Acad. Sci. India 57:86-91.

15. Halila, M. H., and Strange, R. N. 1996. Identification of the causal agent of wilt of chickpea in Tunisia as Fusarium oxysporum f. sp. ciceri race 0. Phytopathol. Mediterr. 35:67-74.

16. Haware, M. P. 1990. Fusarium wilt and other important diseases of chickpea in the Mediterranean area. Options Méditerr. Sér. Sémin. 9:61-64.

17. Haware, M. P., and Nene, Y. L. 1980. Influence of wilt at different stages on the yield loss in chickpea. Trop. Grain Legume Bull. 19:38-40.

18. Haware, M. P., and Nene, Y. L. 1982. Races of Fusarium oxysporum f. sp. ciceri. Plant Dis. 66:809-810. 
19. Jalali, B. L., and Chand, H. 1992. Chickpea wilt. Pages 429-444 in: Plant Diseases of International Importance. Vol. I. Diseases of Cereals and Pulses. U. S. Singh, A. N. Mukhopadhayay, J. Kumar, and H. S. Chaube, eds. Prentice Hall, Englewood Cliffs, NJ.

20. Jiménez-Díaz, R. M., Alcalá-Jiménez, A. R., Hervás, A., and TraperoCasas, J. L. 1993. Pathogenic variability and host resistance in the Fusarium oxysporum $\mathrm{f}$. sp. ciceris/Cicer arietinum pathosystem. Pages 87-94 in: Proc. Eur. Semin. Fusarium Mycotoxins, Taxonomy, Pathogenicity and Host Resistance, 3rd. Hodowla Róslin Aklimatyzacja i Nasiennictwo. Plant Breeding and Acclimatization Institute, Radzikóv, Poland.

21. Jiménez-Díaz, R. M., Trapero-Casas, A., and Cabrera de la Colina, J. 1989. Races of Fusarium oxysporum f. sp. ciceri infecting chickpeas in southern Spain. Pages 515-520 in: Vascular Wilt Diseases of Plants. NATO ASI Series, Vol. H28. E. C. Tjamos and C. H. Beckman, eds. Springer-Verlag, Berlin.

22. Kaiser, W. J. 1984. Control of Ascochyta blight of chickpea through clean seed. Pages 117-122 in: Ascochyta Blight and Winter Sowing of Chickpeas. M. C. Saxena and K. B. Singh, eds. Martinus Nijhoff/Dr. W. Junk Publishers, The Hague, the Netherlands.

23. Kaiser, W. J., and Hannan, R. M. 1983. Etiology and control of seed decay and preemergence damping-off of chickpea by Pythium ultimum. Plant Dis. 67:77-81.

24. Kranz, J. 1968. Eine Analyse von annuellen Epidemien pilzlicher Parasiten. III. Über Korrelationen zwischen quantitativen Merkmalen von Befallskurven und Ähnlichkeit von Epidemien. Phytopathol. Z. 61:205-217.

25. Kranz, J. 1974. Comparison of epidemics. Annu. Rev. Phytopathol. 12: 355-374.

26. Kranz, J. 1974. The role and scope of mathematical analysis and modeling in epidemiology. Pages 7-54 in: Epidemics of Plant Diseases, Mathematical Analysis and Modeling. J. Kranz, ed. Springer-Verlag, New York.

27. Kranz, J. 1978. Comparative anatomy of epidemics. Pages 33-62 in: Plant Disease, Vol. 2. J. G. Horsfall and E. B. Cowling, eds. Academic Press, London.

28. Kranz, J. 1980. Comparative epidemiology: An evaluation of scope, concepts and methods. Pages 18-28 in: Comparative Epidemiology. A Tool for Better Disease Management. Proc. Session Comparative Epidemiol. 3rd Int. Congr. Plant Pathol. J. Palti and J. Kranz, eds. Centre for Agricultural Publishing and Documentation, Wageningen, the Netherlands.

29. Lebeda, A., and Jendrulek, T. 1987. Application of cluster analysis for establishment of genetic similarity in gene-for-gene host-parasite relationships. J. Phytopathol. 119:131-141.

30. Lebeda, A., and Jendrulek, T. 1988. Application of methods of multivariate analysis in comparative epidemiology and research into field resistance. Z. Pflanzenkrankh. Pflanzenschutz 95:495-505.

31. Madden, L. V., and Campbell, C. L. 1990. Nonlinear disease progress curves. Pages 181-229 in: Epidemics of Plant Diseases, Mathematical Analysis and Modeling, 2nd ed. J. Kranz, ed. Ecological Studies 13. Springer-Verlag, Berlin.

32. Madden, L., and Pennypacker, S. P. 1979. Principal component analysis of tomato early blight epidemics. Phytopathol. Z. 95:364-369.

33. Mora-Aguilera, G., Nieto-Angel, D., Campbell, C. L., Téliz, D., and García, E. 1996. Multivariate comparison of papaya ringspot epidemics. Phytopathology 86:70-78.

34. Navas-Cortés, J. A., Hau, B., and Jiménez-Díaz, R. M. 1997. Influence of soil temperature, inoculum density and virulence of races of Fusarium oxysporum f. sp. ciceris in the development of Fusarium wilt of chickpea. Pages 749-50 in: Proc. Congr. Mediterr. Phytopathol. Union, 10th. Société Française de Phytopathologie, ed. Montpellier, France.

35. Nene, Y. L., and Haware, M. P. 1980. Screening chickpea for resistance to wilt. Plant Dis. 64:379-380.

36. Nene, Y. L., and Reddy, M. V. 1987. Chickpea diseases and their control. Pages 233-270 in: The Chickpea. M. C. Saxena and K. B. Singh, eds. CAB International, Oxon, United Kingdom.

37. Orloci, L. 1975. Multivariate analysis in vegetation research. Dr. W. Junk B. V. Publishers, The Hague, the Netherlands.

38. Padwick, G. W., and Bhagwagar, P. R. 1949. Wilt of gram in relation to date of sowing. Indian J. Agric. Sci. 13:289-290.

39. Saxena, M. C. 1990. Problems and potential of chickpea production in the nineties. Pages 13-27 in: Chickpea in the Nineties: Proc. Int. Workshop Chickpea Improvement, 2nd. International Crops Research Institute for the Semi-Arid Tropics (ICRISAT), Patancheru, India.

40. Singh, K. B., and Dahiya, B. S. 1973. Breeding for wilt resistance in chickpea. Pages 13-14 in: Symposium on Wilt Problem and Breeding for Wilt Resistance in Bengal Gram. Indian Research Institute, New Delhi, India.

41. Sneath, P. H. A., and Sokal, R. R. 1973. Numerical Taxonomy. The Principles and Practice of Numerical Classification. W. H. Freeman and Co., San Francisco, CA.

42. Trapero-Casas, A., and Jiménez-Díaz, R. M. 1985. Fungal wilt and root rot diseases of chickpea in southern Spain. Phytopathology 75:1146-1151.

43. Trapero-Casas, A., and Jiménez-Díaz, R. M. 1986. Influence of sowing date on Fusarium wilt and Ascochyta blight of chickpea in southern Spain. Page 11 in: Poster, Abstracts, Int. Food Legume Conf. L. E. O'Keeffe, and F. J. Muehlbauer, eds. Coll. Agric. Univ. Idaho, Moscow.

44. Vanderplank, J. E. 1963. Plant Diseases: Epidemics and Control. Academic Press, New York.

45. Westerlund, Jr., F. V., Campbell, R. N., and Kimble, K. A. 1974. Fungal root rots and wilt of chickpea in California. Phytopathology 64:432-436.

46. Williams, W. T., ed. 1976. Pattern Analysis in Agricultural Science. CSIRO, Melbourne, Australia, and Elsevier, New York.

47. Zadoks, J. C. 1961. Yellow rust on wheat, studies in epidemiology and physiologic specialization. Neth. J. Plant Pathol. 67:69-256. 